\title{
(6) OPEN ACCESS \\ Adjusting the dose in paediatric care: dispersing four different aspirin tablets and taking a proportion
}

\author{
Jørgen Brustugun, ${ }^{1}$ Nikolai Notaker, ${ }_{1}{ }^{2}$ Lasse Holtan Paetz, ${ }_{1}{ }^{\text {Ingunn Tho, }}{ }^{03}$ \\ Kathrin Bjerknes ${ }^{4}$
}

'Oslo Hospital Pharmacy, Hospital Pharmacies Enterprise, South Eastern Norway, Oslo, Norway

${ }^{2}$ Department of Pharmacy, Faculty of Mathematics and Natural Sciences, University of Oslo, Oslo, Norway

${ }^{3}$ School of Pharmacy, University of Oslo, Oslo, Norway ${ }^{4}$ Hospital Pharmacy Enterprises Norway, Lørenskog, Norway

\section{Correspondence to Dr Jørgen Brustugun, Rikshospitalet, Hospital Pharmacy Oslo, Oslo 0050 Norway; jorgen.brustugun@ sykehusapotekene.no}

Received 18 February 2019 Revised 6 May 2019 Accepted 8 May 2019

EAHP Statement 4: Clinical Pharmacy Services.

\section{ABSTRACT \\ Objectives When caring for children in a hospital} setting, tablets are often manipulated at the ward to obtain the right dose. One example is manipulation of tablets containing the slightly water-soluble substance aspirin, used in paediatric care as an antiplatelet agent. The evidence base, however, for choosing certain tablet formulations and manipulation methods over others for extraction of proportions is lacking. The aim of this study was to investigate the effect of tablet formulation and manipulation technique on the dose accuracy and precision attained when dispersing different commercially available aspirin tablets and extracting a small proportion suitable for children.

Methods The manipulation methods investigated simulated those observed in the paediatric clinic. Four tablet formulations - one chewable, one conventional and two dispersible - were dispersed in $10 \mathrm{~mL}$ water in a medicine measure. On (1) passive dispersion, (2) mixing by stirring with the syringe, or (3) stirring and pumping the dispersion in and out of the syringe, respectively, proportions ( $1 \mathrm{~mL}$ or $2 \mathrm{~mL}$ ) were extracted and the doses recovered were determined using a validated UHPLC (ultra high-pressure liquid chromatography) method. Results Fractions from the four different dispersed aspirin tablet formulations varied from $99 \%$ to $3 \%$ of that intended with the lowest degree of mixing, and from $96 \%$ to $34 \%$ of that intended with the highest degree of mixing. Only the dispersible tablets gave average doses within $20 \%$ of the intended dose

Conclusions Fraction extraction from dispersed aspirin tablets only gave doses within $20 \%$ of intended for the dispersible tablets, and then only for some of the manipulation methods: 'passive dispersion' for the $75 \mathrm{mg}$ dispersible tablet and 'stirring and pumping' for the $300 \mathrm{mg}$ dispersible tablet. The tablets not intended for dispersion gave unsatisfactory results, outside $20 \%$, regardless of manipulation method. The findings underline the importance of considering both tablet formulation and dose extraction technique when manipulations are required.

\section{INTRODUCTION}

C) European Association of Hospital Pharmacists 2019. Re-use permitted under CC BY-NC. No commercial re-use. Published by BMJ.

To cite: Brustugun J, Notaker N, Paetz LH, et al. Eur J Hosp Pharm Sci Pract Epub ahead of print: [please include Day Month Year]. doi:10.1136

ejhpharm-2019-001903
Children are often left without documented and approved medicines because medicines may be developed for use in the adult population only; furthermore, the dosage forms and formulations that are available on the market are frequently not suitable for use in children. This lack of age-appropriate formulations has been a topic of concern for a considerable time. ${ }^{1-3}$ Authorities have tried to improve the situation, for instance through the European Union Paediatric Regulation, ${ }^{4}$ a

\section{What this paper adds}

What is already known on this subject

- Children lack age-appropriate medicines, and because of this dosage forms (eg, tablets) may be manipulated by, for instance, splitting, crushing or dispersing, before a small fraction is withdrawn to obtain a prescribed dose.

- MODRIC (Manipulation of Drugs Required in Children) has provided guidelines for manipulation of tablets, and the guideline recommends that dispersion should only be performed if there is knowledge about 'solubility', 'dispersibility' or 'any special characteristics of the formulation'.

- A previous study found that manipulation through dispersion and fraction extraction of tablets containing the slightly soluble substance aspirin did not result in correct doses 22 ; however, only one tablet formulation was investigated.

What this study adds

- The variation in dose accuracy and dose precision that can be encountered when aspirin tablets are dispersed and a fraction $(10 \%$ or $20 \%$ of the whole tablet) is withdrawn as a paediatric dose is illustrated for four different commercially available aspirin tablets (one conventional, one chewable and two dispersible) and three different mixing procedures.

- The dose accuracy varied markedly for the different kinds of tablets, and only fractions taken from the dispersible aspirin tablets came within $20 \%$ of the intended dose.

- Fractions taken from dispersions of the conventional and chewable tablets did not reach this level of accuracy, regardless of mixing procedure. 
manipulated prior to administration, ${ }^{10-13}$ and the practice seems likely to continue for the foreseeable future.

Off-label and unlicensed use of medicines has received some attention through the years, but the practice of manipulation seems to have received less so. In the instances where manipulation has been studied, the focus has mainly been on the effect of tablet splitting. ${ }^{14-18}$ The British initiative Manipulation of Drugs Required in Children (MODRIC) - A Guide for Health Professionals has provided useful guidance on the manipulation of tablets to children, ${ }^{19}$ recommending for instance that 'Tablets should be split in preference to dispersing or crushing tablets and taking a proportion'. In paediatric care, however, the splitting of tablets is often just the first step in the administration; further or other manipulations, like dispersion and dose extraction, may be required. For questions relating to this, MODRIC recommends consulting 'Manufacturers and/or pharmacists'. ${ }^{19}$ And indeed, the question is often raised in the daily life in the clinic, but the evidence base for making recommendations regarding different formulations is limited, also for the hospital pharmacist.

Aspirin has previously been found to be manipulated in paediatric care in our clinic. ${ }^{13}$ In this population, aspirin is used as an antithrombotic agent for a variety of congenital and acquired cardiac conditions. ${ }^{20}$ Although the substance is generally contraindicated in children below 16 years of age because of its association with Reye's syndrome, both children and neonates are sometimes treated with aspirin for the antiplatelet effect. ${ }^{21}$ As the dose in both neonates and children is $1-5 \mathrm{mg} / \mathrm{kg}$ once daily, the treatment may necessitate proportions of tablets to be given. These proportions, smaller than a quarter tablet, may require dispersion and extraction of a fraction.

Broadhurst $e$ t $a l^{22}$ have previously studied manipulation effects for one dispersible tablet formulation containing aspirin. In our local paediatric wards, it was noted that different formulations were used in children dependent on what they had available on the shelf at the ward. The aim of the current study was therefore to investigate the effects of tablet formulation on dose accuracy and precision attained in a fraction extraction. As some of the tablet formulations do not easily disperse, and mixing of tablet dispersions was performed in a not standardised manner at the ward, the effect of mixing was also investigated. Four different aspirin tablet types were investigated in the study, selected based on paediatric use in the clinic and availability in the European market.

By studying aspirin tablets, the results previously presented for one dispersible tablet ${ }^{22}$ could be expanded on with data both for different tablet formulations and mixing procedures. In addition, aspirin was deemed an interesting model substance with regard to manipulation as it is relatively hydrophobic (soluble $1: 300$ in water), ${ }^{23}$ a fact that could accentuate undesirable effects arising during manipulation (eg, problems relating to poor dissolution or high sedimentation rate).

\section{MATERIALS}

Acetylsalicylic acid ( $\geq 99.0 \%)$ and salicylic acid ( $\geq 99.0 \%)$ were provided by Sigma-Aldrich (St Louis, Missouri, USA). Orthophosphoric acid (85\%) and potassium dihydrogen phosphate were provided by Merck (Darmstadt, Germany) or Sigma-Aldrich (Fluka). Methanol, HPLC grade (high-pressure liquid chromatography), was provided by Rathburn Chemicals (Walkerburn, Scotland). Hydrogen peroxide 30\% was provided by VWR AnalaR Normapur, VWR International (Fontenay-sousBois, France).

The tablets investigated were Dispersible Aspirin $75 \mathrm{mg}$ (Aspar Pharmaceuticals, London, UK); Bayer Chewable $81 \mathrm{mg}$ (Bayer Healthcare, Morristown, New Jersey, USA); Disprin $300 \mathrm{mg}$ (Reckitt Benckiser Healthcare (UK), Hull, UK); and Aspirin 500 mg (Bayer, Solna, Sweden). Further information regarding the tablets is summarised in table 1.

\section{METHODS}

The UHPLC (ultra high-pressure liquid chromatography) system was provided by Shimadzu (Kyoto, Japan) and consisted of a Nexera SIL-30AC autosampler, a Nexera LC-30AD pump, a Prominence SPD-M20A UV-DAD (diode array) detector (set at $230 \mathrm{~nm}$ ), a Prominence DGU-20A5R degassing unit and a Prominence CTO-20AC oven. The chromatographic system was operated with LabSolutions LC/GC V.5.42 software. The separation was performed using a C18-AR column (ACE C18-AR Excel $2 \mu \mathrm{m}, 2.1 \times 100 \mathrm{~mm}$, Advanced Chromatography Technologies, Aberdeen, Scotland). The mobile phase consisted of methanol:phosphate buffer ( $\mathrm{pH} 2.0)$ (30:70, v/v). Each chromatographic separation was performed in $8 \mathrm{~min}$. The sample volume was 1 $\mu \mathrm{L}$ and the flow rate was $0.36 \mathrm{~mL} / \mathrm{min}$. The sample cooler was set to $4^{\circ} \mathrm{C}$ and the column oven was set to $40^{\circ} \mathrm{C}$.

The experiments used a Sartorius CPA225D-0CE analytical balance (Sartorius, Göttingen, Germany), a Metrohm 691 $\mathrm{pH}$ metre (Metrohm, Herisau, Switzerland) and a Branson 5510 bath (Branson Ultrasonics, Eemnes, The Netherlands). Diameter and height of tablets were measured with a Cocraft digital calliper $(0-150 \mathrm{~mm}$, accuracy: $0.03 \mathrm{~mm})$. The $\mathrm{TBH}$ 125 tablet hardness tester, Erweka TA friability tester and the Erweka ZT3-2 disintegration tester used for physical characterisation were from Erweka (Heusenstamm, Germany). The oral syringes were Baxter Exactamed $(1 \mathrm{~mL}$ and $5 \mathrm{~mL}$ ) from Baxter Healthcare (Zürich, Switzerland). The medicine measure was a

Table 1 Description of the four tablets included in the study: formulation type, aspirin content and excipients

\begin{tabular}{lllll}
\hline & Dispersible Aspirin (Aspar) & Bayer Chewable (Bayer) & Disprin (Reckitt Benckiser) & Aspirin (Bayer) \\
\hline Formulation type & Dispersible tablet. & Chewable tablet. & Dispersible tablet. & Conventional tablet. \\
Aspirin form & Acetylsalicylic acid. & Acetylsalicylic acid. & Acetylsalicylic acid. & Acetylsalicylic acid. \\
Aspirin content & $75 \mathrm{mg}$ & $81 \mathrm{mg}$ & $300 \mathrm{mg}$ & $500 \mathrm{mg}$ \\
Excipients & Calcium carbonate. & Colloidal silica. & Calcium carbonate. & Cellulose. \\
& Starch. & Corn starch. & Corn starch. & Corn starch. \\
& Citric acid. & Microcrystalline cellulose. & Citric acid. & Saccharine. \\
& Sodium saccharine. & Dextrose. & Sodium lauryl sulfate. & Talc. \\
& Sodium lauryl sulfate. & Sodium saccharine. & Flavour. & Polyvinylpolypyrrolidone. \\
& Talc. & Colourants: D\&C Red No 27 Aluminum & \\
& & Lake, FD\&C (Food, drugs and cosmetics) & Lime flavour. & \\
& Red No 40 Aluminum Lake. & & \\
\end{tabular}


polypropylene medicine measure (Diameter: $38 \mathrm{~mm}$, Hight: 42 mm, $30 \mathrm{~mL}$ ) from Hammarplast Medical (Linköping, Sweden).

\section{Validation of the chromatographic method}

Linearity $\left(r^{2}>0.999\right)$ was demonstrated over the sample concentrations $0.5 \mu \mathrm{g} / \mathrm{mL}-0.125 \mathrm{mg} / \mathrm{mL}$, and the limit of quantification was $<0.5 \mu \mathrm{g} / \mathrm{mL}$, as a ratio of signal to noice $(\mathrm{S} / \mathrm{N})>10$ was found at this concentration. Specificity was validated with regard to tablet excipients of all four tablets, and by subjecting aspirin to heat, hydrogen peroxide $(3 \%)$ or alkaline conditions. The stress conditions produced salicylic acid. Resolution between aspirin and salicylic acid was $>8$ for all samples. The precision was demonstrated determining the aspirin content of powdered Bayer Chewable tablets. The relative SD was $<1 \%$ $(\mathrm{n}=3$ samples), $<1 \%(\mathrm{n}=3$ days $)$ and $0.3 \%(\mathrm{n}=6$ injections from the same sample vial). Sample stability was established for a period of at least 14 hours. Validated linearity covered doses down to at least $1 \%$ of the intended dose for all four tablets, and up to $125 \%$ for Disprin and Aspirin, up to at least $154 \%$ for Bayer Chewable, and up to at least 166\% for Dispersible Aspirin.

\section{Tablet characterisation}

The crushing strength $(\mathrm{N})$, disintegration time (s) and friability were tested according to European Pharmacopoeia (9.0) (PhEur). To allow for comparison between tablets with various dimensions, tensile strength $\left(\mathrm{N} / \mathrm{mm}^{2}\right)$ was calculated from breaking strength $(\mathrm{N})$, tablet diameter $(\mathrm{mm})$ and height $(\mathrm{mm})$, according to Fell and Newton. ${ }^{24}$ The $\mathrm{pH}$ of the dispersion resulting from dispersing one tablet in purified water $(10 \mathrm{~mL})$ was recorded; the $\mathrm{pH}$ of purified water was $6.28 \pm 0.61$ (mean $\pm \mathrm{SD}, \mathrm{n}=7$ ).

\section{Manipulation studies}

The manipulation procedures in this study were designed to be a standardised representation of various non-standardised manipulation practices that are performed in our hospital wards. Observation of manipulations being performed on the ward, as well as interviews with both nurses and clinical pharmacists, provided information regarding the normal procedures used. Doses of $10 \%$ and $20 \%$ of the full tablets were chosen as representatives of 'small tablet fractions not covered by half or quarter tablets'.

In line with Broadhurst et $a l^{22}$ in a $30 \mathrm{~mL}$ graduated plastic medicine measure, a single aspirin tablet was placed in $10 \mathrm{~mL}$ purified water for $3 \mathrm{~min}$. Three minutes was chosen in our study as it was a time sufficient for all four tablet types to disintegrate-and a time that would facilitate comparison with the results previously obtained by Broadhurst et al. ${ }^{22}$ Each sample was agitated in one of three different ways; it was subjected to either of the following:

1. 'Passive dispersion', with no agitation being performed before either a $1 \mathrm{~mL}$ or a $2 \mathrm{~mL}$ sample was withdrawn.

2. Mixing by 'stirring' with the oral syringe during the 3 min disintegration time (10 s every minute) before a $1 \mathrm{~mL}$ sample was withdrawn.

3. Mixing by 'stirring and pumping', stirring with the oral syringe during the 3 min disintegration time (10 s every minute), and 'pumping' the liquid in and out of the syringe four times at the end of the 3 min period, before a $1 \mathrm{~mL}$ or $2 \mathrm{~mL}$ dose was withdrawn.

The $1 \mathrm{~mL}$ and $2 \mathrm{~mL}$ samples were withdrawn with $1 \mathrm{~mL}$ and $5 \mathrm{~mL}$ oral syringes, respectively (the syringes being accurate to $\pm 5 \%$ ). In the medicine measure-divided into five zones from the bottom (zone 1) to the top (zone 5), as outlined by Broadhurst

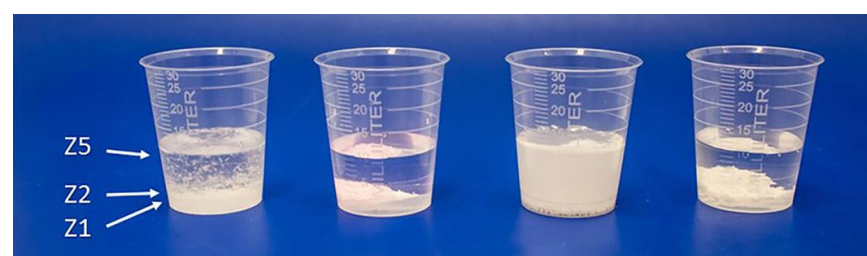

Figure 1 The four aspirin tablets upon passive dispersion in $10 \mathrm{~mL}$ purified water for 3 minutes. From left to right: DispersibleAspirin (75 mg), Bayer Chewable (81 mg), Disprin (300 mg), Aspirin (500 mg). Zones 1, 2 and 5 are marked $Z 1, Z 2$ and Z 5, respectively.

et $a l^{22}$ - the syringes were held vertically and the fraction was extracted from 'Zone 2' of the medicine measure (ie, at the 2 $\mathrm{mL}$ mark) (figure 1). Six medicine measures, each containing one tablet, were prepared both for each tablet formulation and each type of manipulation. One sample was withdrawn from each medicine measure and the aspirin content of the sample was determined in triplicate. The content of each extracted dose was determined as described in the Preparation of samples from extracted tablet fractions section.

From samples both stirred and subjected to 'pumping' (treatment 3, above), $1 \mathrm{~mL}$ samples were also withdrawn from zone 1 and zone 5, respectively, to explore the effect of extraction zone.

\section{Preparation of samples from extracted tablet fractions}

The sample-'the dose', for example, a suspended tablet proportion withdrawn with an oral syringe-was transferred to a 100 $\mathrm{mL}$ volumetric flask. Mobile phase $(70-80 \mathrm{~mL})$ was added and the flask was vigorously shaken for $1 \mathrm{~min}$. The flask was ultrasonicated at ambient room temperature for $30 \mathrm{~min}$. It was again vigorously shaken for $1 \mathrm{~min}$ before mobile phase was added to a final volume of $100 \mathrm{~mL}$. The liquid was again mixed thoroughly. Of the sample solution, $5 \mathrm{~mL}$ was transferred to a $10 \mathrm{~mL}$ test tube and centrifuged (2500 rpm (rotations per minute) ) for $5 \mathrm{~min}$. The supernatant was transferred undiluted to an injector vial, or further diluted in mobile phase-when necessary-to target concentrations of $0.075 \mathrm{mg} / \mathrm{mL}$ (Dispersible Aspirin), $0.081 \mathrm{mg}$ / $\mathrm{mL}$ (Bayer Chewable) or $1.00 \mathrm{mg} / \mathrm{mL}$ (Disprin and Aspirin).

For every manipulation experiment, three control samples consisting of tablet powder equal to one average tablet mass were prepared as described above. The tablet powder in these samples always came from the same lot as the tablets manipulated in the same experiment. A new standard curve from a freshly prepared stock solution was prepared for each new chromatographic analysis. One hundred milligrams $(\geq 99.0 \%)$ of aspirin were dissolved in mobile phase in a $100 \mathrm{~mL}$ volumetric flask. This $1.00 \mathrm{mg} / \mathrm{mL}$ aspirin solution was further diluted to $0.2 \mathrm{mg} / \mathrm{mL}$ in mobile phase. From this stock solution the standard curve was prepared.

\section{Definitions}

Dose accuracy was defined as the closeness of the average dose obtained (\%) to the intended dose (a fifth or a tenth of a tablet). Dose precision was defined as the variation around the average dose obtained and the result is given as both the lowest-highest value and SD.

\section{RESULTS}

\section{Physical properties of the tablets}

The physical properties of the tablets are presented in table 2 . The $\mathrm{pKa}$ of aspirin was $3.5,{ }^{23}$ and the $\mathrm{pH}$ of a dispersed tablet was above the pKa value for two of the tablets (Dispersible 
Table 2 Characteristics of the four aspirin tablets included in the study

\begin{tabular}{|c|c|c|c|c|}
\hline & Dispersible Aspirin (Aspar) & $\begin{array}{l}\text { Bayer Chewable } \\
\text { (Bayer) }\end{array}$ & Disprin (Reckitt Benckiser) & Aspirin (Bayer) \\
\hline Weight $(\mathrm{g})^{*}$ & $0.150 \pm 0.003$ & $0.228 \pm 0.002$ & $0.473 \pm 0.003$ & $0.597 \pm 0.003$ \\
\hline $\begin{array}{l}\text { Dimensions, diameter } \times \text { height } \\
(\mathrm{mm}) \dagger\end{array}$ & $7.03 \times 2.90$ & $8.00 \times 4.25$ & $12.80 \times 2.70$ & $12.06 \times 4.90$ \\
\hline $\mathrm{pH}$ of dispersed tablet $¥$ & 4.60 & 3.02 & 4.96 & 2.84 \\
\hline Friability (\%)§ & $0.44(n=42)$ & $0.07(n=29)$ & $0.84(n=14)$ & $0.11(n=11)$ \\
\hline Disintegration time $(\mathrm{s}) \uparrow$ & $31(25-38)$ & $34(26-40)$ & $30(23-35)$ & $6(5-10)$ \\
\hline Tensile strength $\left(\mathrm{N} / \mathrm{mm}^{2}\right)^{* *}$ & $1.45(1.26-1.62)$ & $1.58(1.21-1.78)$ & $1.22(1.03-1.36)$ & $0.87(0.78-0.93)$ \\
\hline
\end{tabular}

${ }^{*}$ Mean $(\mathrm{g}) \pm \mathrm{SD}(\mathrm{n}=8)$.

tMean, $\mathrm{n}=3 ; \mathrm{SD} \%<1.5 \%$.

$\neq \mathrm{pH}$ of one tablet suspended in $10 \mathrm{~mL}$ purified water $(n=1) ; \mathrm{pH}$ of purified water: $6.28 \pm 0.61$ (average $\pm S D)(n=7)$.

$\S$ Per cent lost on friability testing (PhEur 9.2) (n, according to PhEur).

ๆAverage time $(s)$ to disintegrate $(n=6)$ (low-high).

${ }^{* *}$ Calculated from breaking strength $(\mathrm{N})$, diameter $(\mathrm{mm})$ and height $(\mathrm{mm})$. Average values are given $(\mathrm{n}=10)(\mathrm{low}-\mathrm{high})$.

PhEur, European Pharmacopoeia.

Aspirin and Disprin) and below the pKa for the other two tablets. The tablets varied in tensile strength; the strongest (Bayer Chewable) were approximately double the mean tensile strength of the weakest (Aspirin). Regarding friability, all tablets showed less than the $1 \%$ weight loss generally accepted in PhEur. The tablets with the lowest tensile strength (Aspirin) disintegrated faster than the rest of the tablets. All tablets disintegrated well within 3 min — the hold time in the manipulation experiments (figure 1).

\section{Control samples}

For every assay performed, the content of three ground-up tablet masses $(n=3)$ equal to one whole tablet was determined, with no manipulation being performed. The following were the recoveries obtained for these samples (mean (SD) (lowesthighest value)): $100.3 \%(0.9)(98.7-101.3)(\mathrm{n}=15)$ for Dispersible Aspirin (75 mg), 98.5\% (1.6) (96.3-101.2) ( $\mathrm{n}=12)$ for Bayer Chewable (81 mg), 99.3\% (1.9) $(97.3-103.0)(n=12)$ for Disprin (300 mg), and 99.9\% (4.5) (88.8-104.4) ( $\mathrm{n}=12)$ for Aspirin $(500 \mathrm{mg})$.

Dose accuracy and precision on extraction of a tablet fraction Manipulating aspirin tablets to obtain paediatric doses by extraction of a part from a dispersed tablet led to variations in dose accuracies both between the tablet formulations manipulated and the manipulation methods used (tables 3 and 4).

\section{Dose accuracy}

The tablet formulation giving the most accurate dose was the dispersible tablet, Dispersible Aspirin. For this tablet, the accuracy varied between $71.1 \%$ and $98.7 \%$ (mean, $n=6$ ) of the intended dose for the three different mixing methods explored. The least accurate doses were observed when the conventional aspirin tablet (Aspirin) was manipulated, where an average dose of 3.4\% was found (table 3). Doses extracted after more extensive mixing were generally more accurate; the exception to this was the dispersible tablet, Dispersible Aspirin, where more mixing gave a less accurate dose (table 3).

\section{Dose precision}

The dose precision also showed substantial variation depending on the formulation type and mixing method. For the method with the highest accuracy $(98.7 \%$, obtained by direct extraction from the lowest dosed dispersible tablet), the dose range for six equally treated samples was found to be approximately $20 \%$ above or below the intended dose $(80.0 \%-117.3 \%, \mathrm{n}=6)$. More substantial variations in the doses obtained were found for other tablets, particularly for the chewable tablet and the conventional tablet (table 3). In one instance, doses ranging from $14.8 \%$ to $116.0 \%$ of that intended were found for the same manipulation method and tablet type ('mixing by stirring' of the chewable tablets).

Extraction of the sample at different levels in the medicine measure also contributed to variation in the achieved dose (table 4). In general, extracting the dose from near the bottom (zone 1) resulted in a higher, more accurate dose than extracting near the top (zone 5). The differences seen between $1 \mathrm{~mL}$ and 2 $\mathrm{mL}$ samples, a tenth and a fifth of a tablet, respectively, were less noteworthy (table 3).

\section{DISCUSSION}

The results obtained in this study illustrate that both dose accuracy and dose precision may be compromised when a small dose is extracted as a proportion of a dispersed tablet (tables 3 and 4). Thus, in general it appears that the value of prescribing a small

Table 3 Dosage accuracy and precision attained after suspending a tablet in $10 \mathrm{~mL}$ water and extracting a fraction: $1 \mathrm{~mL}$ or $2 \mathrm{~mL}$, a tenth or a fifth of a tablet constituting the intended dose

\begin{tabular}{llllll}
\hline & Direct extraction & Direct extraction & Stirring & Stirring and pumping & Stirring and pumping \\
\hline Volume extracted & $1 \mathrm{~mL}$ & $2 \mathrm{~mL}$ & $1 \mathrm{~mL}$ & $1 \mathrm{~mL}$ & $2 \mathrm{~mL}$ \\
\hline Dispersible Aspirin $75 \mathrm{mg}$ & $98.7 \pm 14.5(80.0-117.3)$ & $92.2 \pm 13.3(76.0-113.3)$ & $83.4 \pm 8.4(70.7-92)$ & $71.1 \pm 4.3(66.7-78.7)$ & $72.9 \pm 3.1(69.3-77.3)$ \\
Bayer Chewable $81 \mathrm{mg}$ & $9.3 \pm 6.4(6.2-22.2)$ & $12.4 \pm 9.6(4.9-28.4)$ & $36.2 \pm 39.5(14.8-116.0)$ & $39.9 \pm 17.0(23.5-66.7)$ & $34.2 \pm 6.6(23.5-42.0)$ \\
Disprin $300 \mathrm{mg}$ & $45.7 \pm 2.6(43.3-49.9)$ & $55.0 \pm 3.6(50.7-60.8)$ & $73.4 \pm 9.3^{*}(67.2-89.5)$ & $89.0 \pm 5.3(80.5-95.8)$ & $95.5 \pm 2.7(92.7-98.9)$ \\
Aspirin $500 \mathrm{mg}$ & $3.4 \pm 1.1(2.5-5.6)$ & $7.7 \pm 4.1(3.3-14.4)$ & $13.0 \pm 7.3(9.2-27.8)$ & $43.2 \pm 12.4(20.9-54.1)$ & $37.3 \pm 21.8(20.6-79.8)$ \\
\hline
\end{tabular}

Per cent of intended dose \pm SD (lowest-highest value) $(n=6)$ is given. All samples were extracted from zone 2 of the medicine measure.

${ }^{*} n=5$. 
Table 4 Effect of extraction zone: dosage accuracy and precision attained after suspending a tablet in $10 \mathrm{~mL}$ water and extracting a fraction: $1 \mathrm{~mL}$, a tenth of a tablet being the intended dose

\begin{tabular}{lll}
\hline & Zone 1, bottom & Zone 5, top \\
\hline Dispersible Aspirin 75 mg & $83.4 \pm 11.1(71.3-101.3)$ & $72.5 \pm 3.6(66.7-76.0)$ \\
Bayer Chewable $81 \mathrm{mg}$ & $44.9 \pm 13.9(27.2-65.4)$ & $28.8 \pm 9.4(18.5-43.2)$ \\
Disprin $300 \mathrm{mg}$ & $94.2 \pm 8.2^{*}(85.5-105.6)$ & $86.8 \pm 4.2(80.5-91.0)$ \\
Aspirin $500 \mathrm{mg}$ & $72.4 \pm 88.3(10.4-209.5+)$ & $26.2 \pm 11.5(13.3-47.4)$ \\
\hline
\end{tabular}

Per cent of intended dose \pm SD (lowest-highest value) $(n=6)$ is given for dose extractions from zone 1 (bottom of dispersion) or zone 5 (top of the dispersion). All samples were agitated (stirred and pumped) before the extraction.

${ }^{*} \mathrm{n}=5$

†Estimated value, outside validated range.

tablet fraction should always be weighted against the risk of obtaining an inaccurate dose, and sometimes a gravely inaccurately one, at that. The results further illustrate that several factors may be important when tablets are manipulated. For drug substances with challenges regarding solubility, such as aspirin in the tablets investigated here, the type of formulation, the mixing procedure and the details concerning the extraction procedure could affect the result. Because of this, it is important both to select the most suitable tablet formulation and to standardise the manipulation procedure to make therapy safe, in particular for children.

In the absence of a generally accepted level of accuracy for fraction doses from manipulated tablets, $\pm 20 \%$ from intended dose was chosen. This interval was recently used by Watson et $a l^{25}$ to judge the acceptability of fraction doses obtained from dispersed hydrocortisone tablets. A level of $20 \%$ is also midway between the inner $( \pm 15 \%)$ and outer $( \pm 25 \%)$ acceptance limits for tablet parts from tablets with break marks outlined in PhEur, ${ }^{26}$ and although none of the tablets in this study were approved for splitting these pharmacopoeial limits were deemed to provide additional context regarding acceptable deviation in dose for fractions of tablets.

Regarding the different formulations in this study, the dispersible tablet Dispersible Aspirin gave the most accurate dose on extraction of a fraction ( $98.7 \%$ of the tenth of a tablet aimed at). As this is a tablet made with dispersion in mind, this finding may not be surprising. The poor result obtained for the conventional tablet (Aspirin), even after mixing (at best 43.2\%), is more noteworthy. Notable too is the poor results obtained for the chewable tablet (Bayer Chewable) - a tablet that with its low dose (81 $\mathrm{mg}$ ) could be thought attractive in a paediatric care setting. For this tablet, only $39.9 \%$ of the intended dose was attained on average, even after the most extensive mixing procedure used. As a general notice, fraction extraction only gave satisfactory doses for the dispersible tablets, and then only when certain manipulation methods were used-passive dispersion for Dispersible Aspirin, and stirring and pumping for Disprin; for the tablets not intended for dispersion, fraction extraction gave unsatisfactory results, outside $\pm 20 \%$ of the intended dose, regardless of manipulation method.

The variations observed are probably influenced by formulation excipients. For example, the two dispersible tablets both contained citric acid and calcium carbonate, a system developing carbon dioxide gas that through agitation will improve homogeneity of the tablet dispersion. The dispersions resulting from the different tablets also had different $\mathrm{pH}$ values, probably caused by individual excipients such as calcium carbonate. In this study, the tablet dispersions spanned two $\mathrm{pH}$ units, from 3.0 to 5.0, a range encompassing the $\mathrm{pKa}$ of the active ingredient in question, aspirin, with its $\mathrm{pKa}$ of 3.5. This could explain some of the variations in accuracy observed as the solubility of aspirin depends on its protonation-the solubility of aspirin itself being given as $1 \mathrm{~g}$ in $300 \mathrm{~mL}$ water (ie, $33.3 \mathrm{mg}$ in $10 \mathrm{~mL}$ ), while inorganic salts of the substance are stated to be 'soluble'. ${ }^{23}$ Defining 'soluble' as $1: 10-1: 30,{ }^{27}$ a solubility of $1 \mathrm{~g}$ in $10-30 \mathrm{~mL}$ is reached (ie, $1000 \mathrm{mg}-333 \mathrm{mg}$ in $10 \mathrm{~mL}$ ), and as the aspirin content in the tablets fell between $75 \mathrm{mg}$ and $500 \mathrm{mg}$, the $10 \mathrm{~mL}$ water used in the experiments would not be sufficient to dissolve the protonated aspirin at $\mathrm{pH}$ values below $\mathrm{pKa}$. At $\mathrm{pH}$ values above the $\mathrm{pKa}$, however, as at $\mathrm{pH} 4.6-5.0$ seen for dispersions of the dispersible tablets, better solubility would be expected, and with that better dose accuracy-as is indeed observed even for the $300 \mathrm{mg}$ dispersible tablet (Disprin). On the other hand, reduced solubility at low $\mathrm{pH}$ may well have contributed to the low dose accuracy for both the conventional aspirin tablet (Aspirin) and the chewable tablet (Bayer Chewable) as the $\mathrm{pH}$ was 3.0 or lower for the dispersions of these tablets (table 2). With reduced solubility, increased sedimentation and dose inhomogeneity could be suspected. The observed differences between doses from the top and bottom zones-being more pronounced for the low $\mathrm{pH}$ dispersions, and in particular for the highest dosed Aspirin tablets (table 4)-support this.

In general, defining sink conditions as $3-10$ times the solubility, ${ }^{28}$ the volumes needed to dissolve drug substances in paediatric manipulations will sometimes be prohibitive considering a neonatal stomach can only contain a limited volume, sometimes estimated to $20 \mathrm{~mL}{ }^{29}$ Because of this, it is likely that some active ingredients will always remain undissolved during a tablet manipulation. The results for the chewable and conventional tablets in this study (tables 3 and 4) illustrate that the dose accuracies obtained in such situations may be poor indeed-and that mixing of the tablet suspensions only has a limited effect. 'Stirring', 'stirring and pumping', and 'pumping' with a $1 \mathrm{~mL}$ oral syringe or a $5 \mathrm{~mL}$ oral syringe all gave doses below $50 \%$ of that intended. Thus, in our experiments, mixing could not compensate if an unsuitable tablet formulation was chosen to begin with.

The samples discussed above (table 3 ) were all extracted from zone 2 of the medicine measure. The situation is further complicated when dose extractions from zone 1 or 5 are considered (table 4 and figure 1). As pointed out, the effect of extraction zone was most pronounced for the tablets where the solubility, because of $\mathrm{pH}$ and aspirin amount, was not favoured. In particular, this is illustrated by the conventional Aspirin tablet where doses extracted from near the bottom of the medicine measure showed a very high variability (table 4 ). The difference between doses from the lowest and uppermost zones approached 50 per cent points for this conventional tablet, even after mixing. This far exceeds the 20 per cent point difference between these zones previously demonstrated on passive dispersion of a dispersible tablet, $^{22}$ a further illustration of the different behaviours of different tablet formulations.

As both this study and the study by Broadhurst et $a l^{22}$ investigated manipulation of dispersible $75 \mathrm{mg}$ aspirin tablets, an estimate of practitioner variability can also be made. In this study the passive dispersion for $3 \mathrm{~min}$ of the dispersible $75 \mathrm{mg}$ tablet followed by extraction of a $1 \mathrm{~mL}$ dose from zone 2 with a $1 \mathrm{~mL}$ syringe yielded $98.7 \%$ of the intended dose. The dose retrieved under comparable conditions by Broadhurst et $a l^{22}$ was $58.5 \%$. This difference could be a genuine expression of person-toperson variability, or possibly an effect of steps in the manipulation process not standardised; it could also be an effect of factors not tied to the manipulation itself, such as differences in the analytical method. 
In general, quantitative determination of the active ingredient in the extracted dose was essential to judge on the success of the manipulations. The physical characteristics (eg, friability, tensile strength and so on) seemed not to be promising candidates as stand-in parameters for 'suitability for manipulation' (table 2).

This study illustrates that the dose accuracy obtained in extracted proportions of dispersed tablets may be influenced by both the manipulation method used, the individual physicochemical properties of the drug substance in question and the type of tablet. Effects of individual excipients and variation between practitioners could possibly come in addition to these. For the aspirin tablets investigated in this study, only a combination of certain tablets (the dispersible ones) with certain manipulation procedures (which could vary) would give doses both accurate and precise. Accepting a deviation from an intended dose of 20\%, only passive dispersion of the Dispersible Aspirin tablet and 'stirring and pumping' of Disprin met the criterion. This highlights the importance of standardising the manipulation practice, both in the method used and the tablet formulation chosen.

\section{Limitations}

Because the different types of tablets were not available in equal strength, tablets with different aspirin content $(75-500 \mathrm{mg})$ were investigated in the study. Comparing the content with the solubility limits, this may have influenced the results to some extent. The main trend did not follow the content gradient, however (table 3); doses deemed acceptable could be extracted both from the lower $(75 \mathrm{mg}$ ) and higher $(300 \mathrm{mg}$ ) dosed dispersible tablets.

The results from the chewable and conventional tablet in this study could possibly be generalised to other drug substances with challenges regarding solubility. However, individual concerns regarding dose, solubility and $\mathrm{pKa}$ of the test substance, aspirin, could limit generalisability, and the study of other drug substances in similar or alternative tablets is of interest.

An additional limitation is that this study only investigated one main manipulation method: dispersing a tablet and withdrawing a fraction from the resulting dispersion. Although this method is not encouraged by the European Medicines Agency, ${ }^{30}$ it was found by MODRIC to be a common practice, constituting more than $50 \%$ of reported tablet manipulations in their survey study. ${ }^{19}$ Alternatives to this method exist, however-for instance, splitting the tablet first before dispersing the fragment and treating the full volume as the dose. Further investigation is therefore necessary to give advice for best practice at the ward.

\section{CONCLUSIONS}

Fraction extraction from dispersed aspirin tablets only gave satisfactory doses, here defined as within $20 \%$ of the intended dose, for the dispersible tablet formulations, and then only for some of the manipulation methods used: 'passive dispersion' for the $75 \mathrm{mg}$ dispersible tablet and 'stirring and pumping' for the 300 mg dispersible tablet. For the tablets not intended for dispersion, fraction extraction gave unsatisfactory results, regardless of manipulation method used. The findings underline the importance of considering both tablet formulation and dose extraction technique when manipulations are required.

Acknowledgements This study has been conducted within the project 'Better Medicines for Children' research initiative of the Hospital Pharmacy Enterprise, Oslo and Akershus University Hospital, Norway. The authors are grateful to the hospital pharmacists Arna Teigen and Cathrine Kjeldby for valuable discussions on manipulation in clinical practice, and to Elisabeth Birkedal Aas for assistance with the physical tablet tests. The collaboration with the Norwegian Medicines for Children Network is greatly appreciated.

Contributors IT, JB and KB: conceived the project, supervised data collection and data analysis, and wrote the manuscript. LHP and NN (equal contributions): performed tablet manipulations, collected, analysed and interpreted the data, and reviewed the manuscript.

Funding The authors have not declared a specific grant for this research from any funding agency in the public, commercial or not-for-profit sectors.

Competing interests None declared.

Patient consent for publication Not required.

Provenance and peer review Not commissioned; externally peer reviewed.

Data availability statement All data relevant to the study are included in the article or uploaded as supplementary information.

Open access This is an open access article distributed in accordance with the Creative Commons Attribution Non Commercial (CC BY-NC 4.0) license, which permits others to distribute, remix, adapt, build upon this work non-commercially, and license their derivative works on different terms, provided the original work is properly cited, an indication of whether changes were made, and the use is noncommercial. See: http://creativecommons.org/licenses/by-nc/4.0/.

\section{REFERENCES}

1 Nahata MC. Lack of pediatric drug formulations. Pediatrics 1999;104:607-9.

2 Standing JF, Tuleu C. Paediatric formulations--getting to the heart of the problem. Int J Pharm 2005:300:56-66.

3 Magalhães J, Rodrigues AT, Roque F, et al. Use of off-label and unlicenced drugs in hospitalised paediatric patients: a systematic review. Eur J Clin Pharmacol 2015;71:1-13

4 European Union Paediatric Regulation. Regulation (EC) NO 1901/2006 of the European Parliament and of the Council of 12 December 2006 on medicinal products for paediatric use, OJ L 378, 27.12.2006; 2006

5 Corny J, Lebel D, Bailey B, et al. Unlicensed and off-label drug use in children before and after pediatric governmental initiatives. J Pediatr Pharmol Ther 2015;20:316-28.

6 Hoppu K, Anabwani G, Garcia-Bournissen F, et al. The status of paediatric medicines initiatives around the world--What has happened and what has not? Eur J Clin Pharmacol 2012;68:1-10.

7 Conroy S, Choonara I, Impicciatore P, et al. Survey of unlicensed and off label drug use in paediatric wards in European countries. European Network for drug investigation in children. BMJ 2000;320:79-82.

8 Kimland E, Nydert P, Odlind V, et al. Paediatric drug use with focus on offlabel prescriptions at Swedish hospitals - a nationwide study. Acta Paediatr 2012;101:772-8.

9 Teigen A, Wang S, Truong BT, et al. Off-label and unlicensed medicines to hospitalised children in Norway. J Pharm Pharmacol 2017;69:432-8.

10 Nunn A, Richey R, Shah U, et al. Estimating the requirement for manipulation of medicines to provide accurate doses for children. Eur J Hosp Pharm 2013;20:3-7.

11 Richey RH, Shah UU, Peak M, et al. Manipulation of drugs to achieve the required dose is intrinsic to paediatric practice but is not supported by guidelines or evidence. BMC Pediatr 2013;13.

12 Richey RH, Hughes C, Craig JV, et al. A systematic review of the use of dosage form manipulation to obtain required doses to inform use of manipulation in paediatric practice. Int J Pharm 2017;518:155-66.

13 Bjerknes K, Bøyum S, Kristensen S, et al. Manipulating tablets and capsules given to hospitalised children in Norway is common practice. Acta Paediatr 2017;106:503-8.

14 Boggie DT, DeLattre ML, Schaefer MG, et al. Accuracy of splitting unscored valdecoxib tablets. Am J Health Syst Pharm 2004;61:1482-3.

15 Hill SW, Varker AS, Karlage K, et al. Analysis of drug content and weight uniformity for half-tablets of 6 commonly split medications. J Manag Care Pharm 2009;15:253-61.

16 Margiocco ML, Warren J, Borgarelli M, et al. Analysis of weight uniformity, content uniformity and 30-day stability in halves and quarters of routinely prescribed cardiovascular medications. J Vet Cardio/ 2009;11:31-9.

17 Verrue C, Mehuys E, Boussery K, et al. Tablet-splitting: a common yet not so innocent practice. J Adv Nurs 2011;67:26-32.

18 Helmy SA. Tablet splitting: is it worthwhile? Analysis of drug content and weight uniformity for half tablets of 16 commonly used medications in the outpatient setting. J Manag Care Spec Pharm 2015:21:76-88.

19 MODRIC - Manipulation of Drugs Required in Children. A guideline for health professionals. Alder Hey Children's NHS Foundation Trust, UK, 2017. Available: http:// www.alderhey.nhs.uk/wp-content/uploads/MODRIC-GUIDELINES-April-2017.pdf [Accessed 27 Feb 2018].

20 Mohanty S, Vaidyanathan B. Anti-platelet agents in pediatric cardiac practice. Ann Pediatr Cardiol 2013;6:59-64.

21 BNF for Children. Aspirin (acetylsalicylic acid). Available: https://www. medicinescomplete.com/ [Accessed 28 Nov 2018]. 
22 Broadhurst EC, Ford JL, Nunn AJ, et al. Dose uniformity of samples prepared from dispersible aspirin tablets for paediatric use. Eur J Hospital Pharm Sci 2008;14:27-31.

23 O'Neal MJ, Smith A, Heckelman PE, eds. The Merck Index: An Encyclopedia of Chemicals, Drugs, and Biologicals. 13th ed. Aspirin. Whitehouse Station, NJ: Merck \& Co., inc, 2001.

24 Fell JT, Newton JM. Determination of tablet strength by the diametral-compression test. J Pharm Sci 1970;59:688-91.

25 Watson C, Webb EA, Kerr S, et al. How close is the dose? Manipulation of $10 \mathrm{mg}$ hydrocortisone tablets to provide appropriate doses to children. Int J Pharm 2018:545:57-63.
26 European Pharmacopoeia. Tablets, Compressi. 01/2018:0478. Available: http://online. edqm.eul [Accessed 16 Apr 2019].

27 European Pharmacopoeia. General notices. 07/2014:10000, corr 9.2. Available: http:/ online.edqm.eu/ [Accessed 31 Mar 2019].

28 European Pharmacopoeia. Recommendations on dissolution testing. 07/2010:51701. Available: http://online.edqm.eu/ [Accessed 1 May 2019].

29 Bergman NJ. Neonatal stomach volume and physiology suggest feeding at 1-H intervals. Acta Paediatr 2013:102:773-7.

30 EMA. EMA/CHMP/QWP/805880/2012 rev. 2. Guideline on pharmaceutical development of medicines for paediatric use 2013. 